\title{
Determination of Fatigue life of Spiral bevel gears used in automotive differential gearbox
}

\author{
Iresh Bhavi*, Vinay Kuppast** and Shivakant Kurbet*** \\ *(Department of Mechanical Engineering, BLDEA 's College of Engineering and Technology, Bijapur-586103 \\ ** (Department of Mechanical Engineering, Basaveshwar Engineering College, Bagalkot-587102 \\ *** (Department of Mechanical Engineering, Basaveshwar Engineering College, Bagalkot-587102
}

\begin{abstract}
This paper describes the experimental destructive testing of spiral bevel gears used in automotive differential gear box. The experimental testing is aimed at early detection of failure of spiral bevel gears during operation by continuously recording and comparing the sound and vibration characteristics during testing. For this purpose, a special fatigue test rig has been developed which can apply dynamic rotational loads with the help of a three phase AC electric motor. The accelerometers located on the drive side (crown pinion) and the slave side (crown wheel) measures the vibration characteristics and an acoustic sensor place near the gears in mesh measures noise levels. The acquired data in time domain are then converted to frequency domain by using a FFT. The signature of failure of pinion was obtained. Three pairs of gears were tested a new gear pair, a used gear pair and a gear pair after breakage of one teeth of pinion. The results obtained show that there is a significant increase in sound and vibration level for used and damaged gear pair. By comparing the results, it is possible for early prediction of point of failure which can be a significant finding in early detection of failure of spiral bevel gears.
\end{abstract}

Keywords -Differential gearbox, Endurance testing, Fatigue life, Finite element analysis, Noise, Spiral bevel gears, Vibration

\section{INTRODUCTION}

Gears are the mechanical components used to transmit rotary power between two shafts without slippage at different speeds, torque, even in different direction depending on their configuration. Bevel gears are widely used in power transmission because of their ability to transmit power between two shafts which are almost at any angle to each other. Spiral bevel gears are main components of power transmission used in almost all automotive differential gear box. Due to the demand for maximum power capacity, reliability and minimum weight the fatigue strength of individual gear is significant. These gears are typically required to operate at extremely high fluctuation of speeds and carry high loads during such operating conditions; hence successful operation of geared system is very important for safety and reliability. Testing and analysis of spiral bevel gears has been an emerging area of research and very scarce open literature is available as compared to that existing for spur and helical gears. This may be due to very complex gear geometry and specialized test equipment necessary to test these components and arrive at proper conclusions.

Failure of a gear during operation results not only in higher cost of replacement or repair but also the down time of the system. Hence early detection of the failure of gear may play a significant role in saving these costs.
Handschuh and Lewicki [1] carried out experimental endurance testing of prototypes of Face gears for feasibility of use in Helicopter transmission. All four gear sets ran successfully at hundred percent of rated speed and torque for thirty million pinion cycles and further thirty million pinion cycles at two hundred percent of rated speed and torque. They measured and compared sound pressure levels and vibration levels at both pinion and slave side during operation. Lewicki.et.al [2] tested experimentally the improved design spiral bevel gears for reduction in weight and noise and increase in life. Improvement in design were achieved by changing the material, modifying fillet radius to reduce stress due to tooth bending and tooth geometry modification to reduce noise by reducing transmission errors. Strain, noise and vibrations were measured and compared with original gears, and a significant reduction in noise and gear stresses were achieved.

Vogel, Griewank and Bar [3] has used a mathematical model for Spiral bevel and Hypoid gears generating process to propose new method to carryout analysis of tooth contact. They have developed a first and second order condition for the contact of gear tooth generated by considering singularity of first order along line of action.

Akata.et.al and Gasparini et.al $[4,8]$ carried out a bending fatigue test of single tooth by using a three-point bending load. It gives very rapid results compared to life tests which are very time consuming 
and expensive. Finite element analysis was carried out to determine stresses in spur gears.

Ural.et. al [5] used linear elastic fracture mechanics theory combined with finite element method to predict and simulate fatigue crack growth in spiral bevel gear. They employed a parallel PCcluster approach to reduce the computation time.

Sureshkumar.et.al [6] carriedout failure analysis of bevel pinion and gear of gearbox of an aero engine. By studying visual inspection, stereobinocular, fractographic, microstructure, hardness and composition they concluded that failure was due to multiple independent fatigue cracks.

Sheveleva.et.al [7] developed algorithms for analysis of contact stress and mesh kinematic and geometrical analysis, based on presentation of contacting surfaces grid and distance between their fields for spiral bevel gears. Classical Hertz contact pressure was found by using first algorithm and second algorithm used boundary element method for finite dimensions elastic solids contact.

Rontu, Szanti and Masa [9,10] has carried out computational analysis of a complete drive line which involves loaded tooth contact analysis and study of tooth contact pattern due relative displacement of gears arising from shaft or bearing deflections. He found that the point contact in the unloaded teeth changes to Hertzian ellipse when the load or temperature changes are applied.

Astoul.et.al [11] proposed a method for simulation of generation and meshing of spiral bevel gears. Based on Fong's approach they formulated a mathematical model for generating tooth surfaces of Spiral bevel and Hypoid gears. They have also proposed a numerical algorithm for contact analysis of unloaded tooth.

Deng.et.al [12] analyzed the contact fatigue on the surface of teeth and the bending fatigue in the root of teeth by proposing a three-dimensional finite element model of straight bevel gear pair based on the cumulative fatigue criterion and stress-life equation. They found that maximum contact fatigue stress occurs near the pitch line and the maximum bending stress occurs at the highest point of single tooth contact for gears. Both the above stresses are directly proportional to operating torque.

Vijayakar [13] determined life and damage due to contact and bending fatigue of spiral bevel gears, by using a software tool Transmission 3D from ANSOL and compared them with experimental results from a fatigue test rig of spiral bevel gears at NASA GR center.

Bhavi.et.al $[14,15,16]$ has reviewed work done so far in the field of analysis and testing of differential gear box of an automobile. They have carried out static and multi body dynamic analysis of differential gear box assembly of Mahindra Bolero and determined the limiting torque at which the gearbox fails. In one paper, they have proposed an experimental setup to determine the fatigue life of spiral bevel gears by using noise and vibration approach. They have tested a pair of spiral bevel gears for its suitability for the required application by running it for several required number of cycles before failure. They have measured the change in characteristics of noise and vibrations produced by the spiral bevel gears pair after specified number of life cycles, which can be used as a basis for early detection of gears failure.

\section{METHODOLOGY}

As limited work has been recorded in the prediction of fatigue life of spur $\&$ helical gears and very scarce work has been recorded for bevel gears which is clear from the literature survey made. Hence in the present work a Fatigue test rig which can apply dynamic (rotational) load as compared to the available static loading test methods which use static fatigue loading for testing of spiral bevel gear pair has been developed.

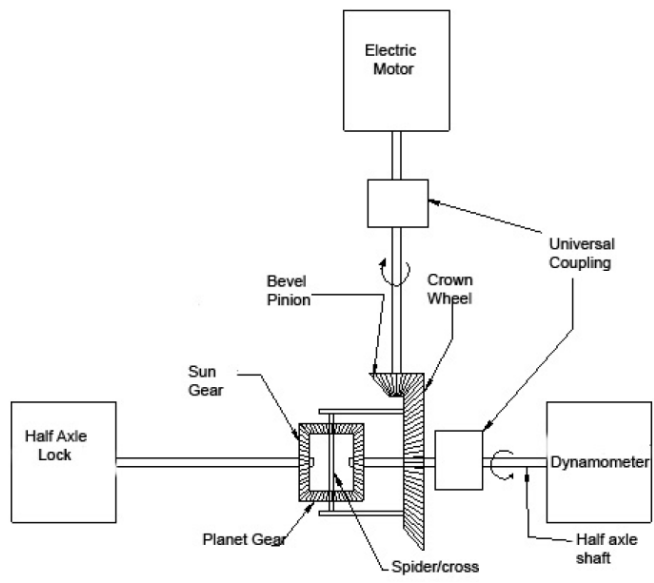

Fig.1 Layout of Experimental setup

Fig. 1 shows the layout of equipments in the experimental setup. Fig.2 and Fig.3 shows the experimental setup that has been developed at Research center, Basaveshwar Engineering College, Bagalkot for testing of spiral bevel gears used as crown pinion and wheel in automotive differential gearbox.

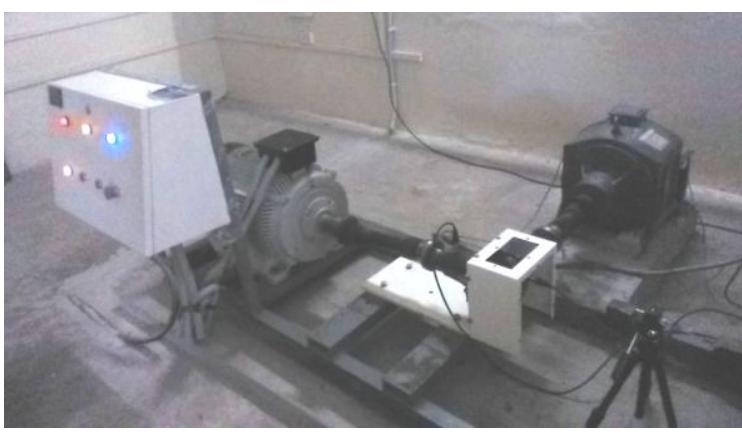

Fig.2 Fatigue test rig 


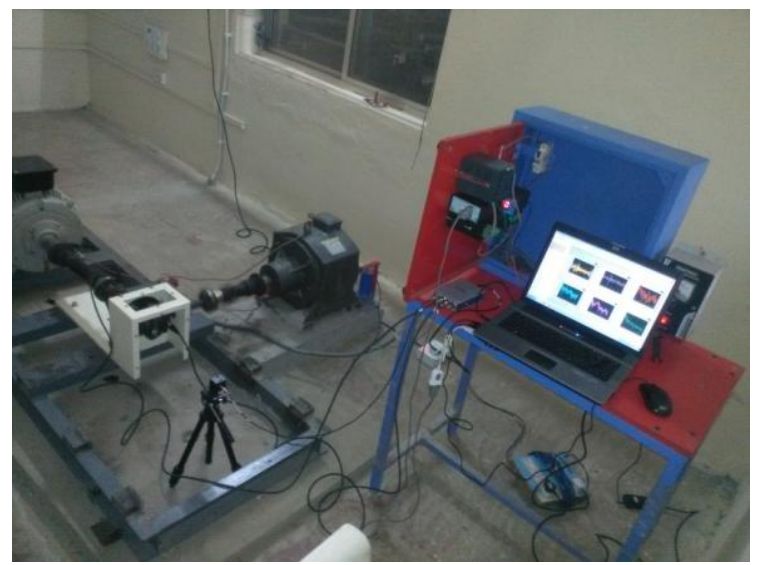

Fig.3 Fatigue test rig with instruments

A three phase AC electric motor is used to supply the driving power which is connected to the input shaft of the pinion and an eddy current dynamometer is used to apply loads on the driven side i.e., crown wheel. The accelerometers located on the drive side (crown pinion) and the slave side (crown wheel) measures the vibration characteristics and an acoustic sensor place near the gears in mesh measures noise levels. The acquired data in time domain are then converted to frequency domain by using a FFT. Three pairs of gears were tested a new gear pair, a used gear pair and a gear pair with one damaged teeth of pinion.

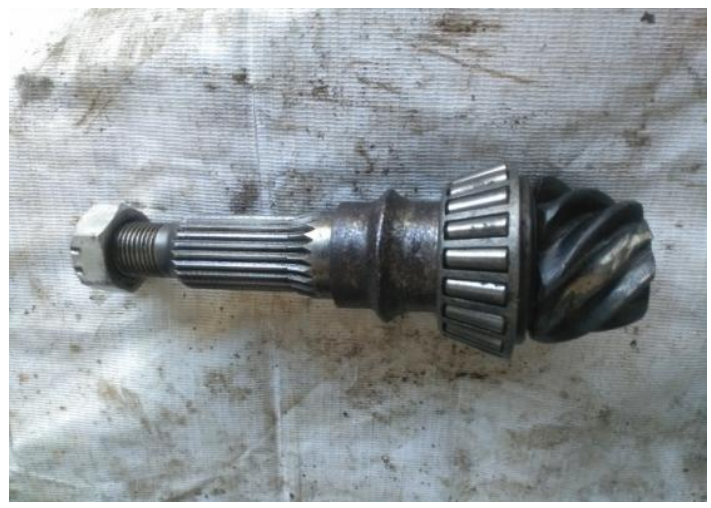

Fig.3 Test pinion with one broken teeth

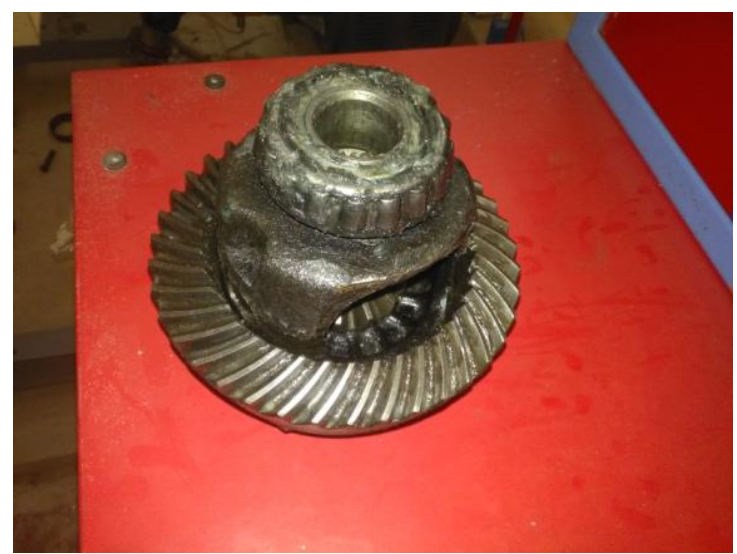

Fig.4 Test Crown gear with cage assembly

\section{RESULTS AND DISCUSSION}

As the maximum rated torque for the given differential gearbox was $37 \mathrm{Nm}$, hence 200 percent of the rated torque i.e., $74 \mathrm{Nm}$ was applied on the drive pinion at $1500 \mathrm{rpm}$. The results of noise spectrum from Fig.5 and vibration spectrum from Fig.6 obtained show that there is a significant increase in sound and vibration level for used crown wheel and pinion pair and further increase in sound and vibration levels gear pair with one broken teeth of the pinion as compared to new pair of crown wheel and pinion. Hence by studying and comparing the noise and vibration spectrum it is possible to know the status of the crown wheel and pinion pair and even a peak rise in noise and vibrations level are observed just prior to failure.

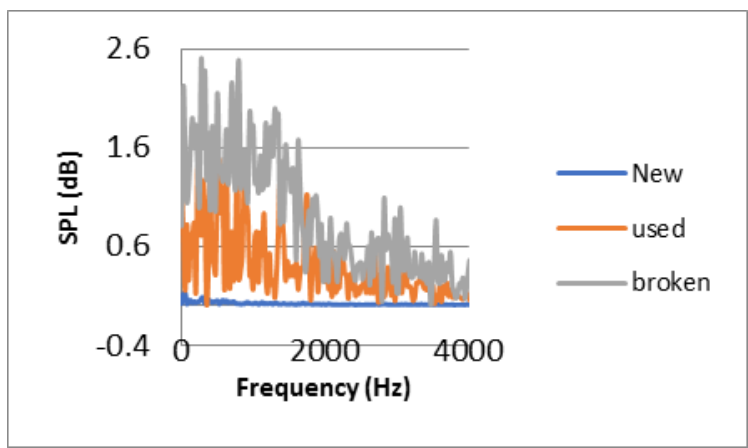

Fig.5 Comparison of noise spectrum

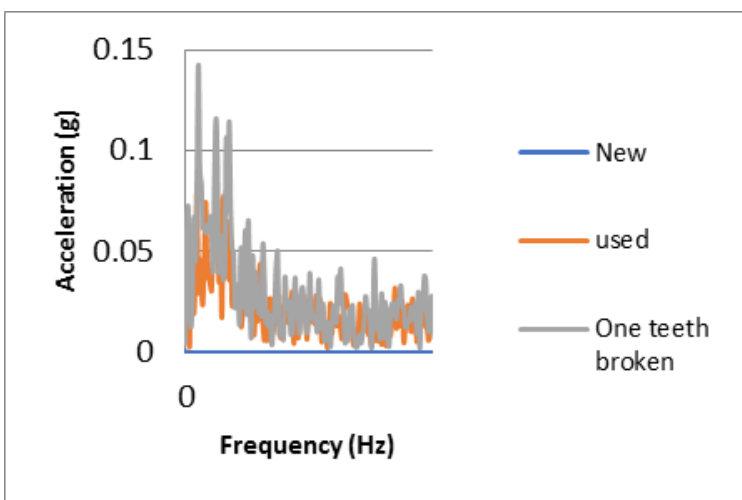

Fig.6 Comparison of Pinion side acceleration

Pitting on the surface of gear tooth was observed after $3 \times 10^{6}$ pinion cycles, which were due to surface fatigue. And at $7.2 \times 10^{6}$ cycles there was failure of one gear tooth of the pinion resulting in peak rise in vibration and sound level.

\section{CONCLUSION}

Following conclusions are drawn from the above work,

a) The given crown wheel and pinion pair showed surface pitting due to fatigue after $3 \times 10^{6}$ pinion cycles and there was breaking of one tooth of the pinion at $7.2 \times 10^{6}$ pinion cycles.

b) Due to additional overlapping of gear tooth in 
case of spiral bevel gears, the gear pair performed well even after the breakage of one teeth of the pinion.

c) The noise and vibrations measured were very low for new set of gears and increased considerably for used gear pairs and there was a very peak rise in noise and vibration level for the damaged gear pair.

d) By studying the sound and vibration spectrum it is possible to know the status of the given spiral bevel gear pair and it is also possible for early detection of failure of given spiral bevel gear pair during operation.

\section{REFERENCES}

[1]. R. Handschuh, D. Lewicki and R. Bossler, Experimental Testing of Prototype Face Gears for Helicopter Transmissions, NASA Technical Memorandum 105434, 1992, Gcearbox Configurations of the 90's, Institute of Mechanical Engineers, Solihull, West Midlands, United Kingdom, October 28, 1992.

[2]. David G. Lewicki, Robert F Handschuh, Zachary S. Henry and Faydor L. Litvin, Low-Noise, High-Strength, Spiral-Bevel Gears for Helicopter Transmissions, NASA Technical Memorandum 106080, 29th Joint Propulsion Conference and Exhibit, Monterey, California, June 28-30, 1993.

[3]. O. Vogel, A. Griewank, G. Bar, Direct gear tooth contact analysis for hypoid bevel gears, Computer Methods in Applied Mechanics and Engineering. 191, 2002, 3965-3982.

[4]. E. Akata, M.T. Altinbalik and Y. Can, Three point load application in single tooth bending fatigue test for evaluation of gear blank manufacturing methods, International Journal of Fatigue 26, 2004, 785-789

[5]. [5] Ani Ural, Gerd Heber, Paul A.Wawrzynek, Anthony R.Ingraffea, David G.Lewicki, Joaquim B.C.Neto, Threedimensional, parallel, finite element simulation of fatigue crack growth in a spiral bevel pinion gear, Engineering Fracture Mechanics 72, 2005, 1148-1170.

[6]. M.Sureshkumar, M.Madan, M A Venkataswamy, M.Sujata and S K Bhaumik, Fatigue fracture of bevel gear of an Aero engine gearbox, Technical Report No: MTFA-1000-05-2006, $1000^{\text {th }}$ investigation at NAL, India.

[7]. Galina I. Sheveleva, Andrey E. Volkov and Vladimir I. Medvedev, Algorithms for analysis of meshing and contact of spiral bevel gears, Mechanism and Machine Theory 42, 2007, 198-215.
[8]. G. Gasparini, U. Mariani, C. Gorla, M. Filippini and F. Rosa, Bending Fatigue Tests of Helicopter Case Carburized Gears: Influence of Material, Design and Manufacturing Parameters, Gear Technology, November/December 2009, 6876.

[9]. Jesse Rontu and Gabor Szanti and Eero Masa and ATA Gears Ltd, Drive Line Analysis for Tooth Contact Optimization of High Power Spiral Bevel Gears, AGMA Technical Paper, October 2010, 10FTM15.

[10]. J. Rontu, G. Szanti and E. Masa, Drive Line Analysis for Tooth Contact Optimization of High-Power Spiral Bevel Gears, Gear Technology, June/July 2011, 56-64.

[11]. Julien Astoul, Jerome Geneix, Emmanuel Mermoz and Marc Sartor, A simple and robust method for spiral bevel gear generation and tooth contact analysis, International Journal on Interactive Design and Manufacturing, Vol 7, Issue 1, February 2013, 37-49.

[12]. DENG Song, HUA Lin, HAN Xing-hui and HUANG Song, Finite element analysis of contact fatigue and bending fatigue of a theoretical assembling straight bevel gear pair, Journal of Central South University, Vol 20, Issue 2, February 2013, 279-292.

[13]. Sandeep Vijayakar, Contact and Bending Durability Calculation for Spiral-Bevel Gears, NASA/CR-2016-219112, June 2016.

[14]. I. G. Bhavi, V.V.Kupast, M. I. Sakri and S.N.Kurbet, Fatigue life estimation and failure analysis of bevel gears used in Differential gear box of an automobile - A Review, Proc. ICDAAME 2011, Karpagam College of Engineering, Thiruvannamalai, 2011, S67.

[15]. Iresh Bhavi and Shivakant Kurbet, Multi Body Dynamic analysis of Differential gear box of an Automobile, Proc. 2011 ANSYS India Users Conference, 2011.

[16]. Iresh Bhavi, Vinay Kuppast and Shivakant Kurbet, Experimental Setup and Methodology to Carryout Fatigue Testing of Spiral Bevel Gears Used in Differential Gear Box Using NVH Approach, Applied Mechanics and Materials, Vol. 852, 2016, 545-550.

[17]. Fletcher Easy Steel - Special Steel Book, (Fletcher Building Ltd, 2008).

[18]. Howard E. Boyer, Atlas of Fatigue Curves (ASM International). 